Article

\title{
Figure of Merit Enhancement of a Surface Plasmon Resonance Sensor Using a Low-Refractive-Index Porous Silica Film
}

\author{
Qing-Qing Meng ${ }^{1}$, Xin Zhao ${ }^{1}$, Cheng-You Lin ${ }^{1, *}$, Shu-Jing Chen ${ }^{2}$, Ying-Chun Ding ${ }^{1}$ \\ and Zhao-Yang Chen ${ }^{1, *}$ \\ 1 College of Science, Beijing University of Chemical Technology, Beijing 100029, China; \\ 2015200897@mail.buct.edu.cn (Q.-Q.M.); 2014200876@mail.buct.edu.cn (X.Z.); \\ dingyc@mail.buct.edu.cn (Y.-C.D.) \\ 2 School of Materials Science and Technology, China University of Geosciences (Beijing), Beijing 100083, China; \\ chenshujing@cugb.edu.cn \\ * Correspondence: cylin@mail.buct.edu.cn (C.-Y.L.); chenzy@mail.buct.edu.cn (Z.-Y.C.); \\ Tel.: +86-186-1008-1530 (C.-Y.L.); +86-150-1144-2703 (Z.-Y.C.)
}

Received: 7 July 2017; Accepted: 8 August 2017; Published: 10 August 2017

\begin{abstract}
In this paper; the surface plasmon resonance (SPR) sensor with a porous silica film was studied. The effect of the thickness and porosity of the porous silica film on the performance of the sensor was analyzed. The results indicated that the figure of merit (FOM) of an SPR sensor can be enhanced by using a porous silica film with a low-refractive-index. Particularly; the FOM of an SPR sensor with $40 \mathrm{~nm}$ thick $90 \%$ porosity porous silica film; whose refractive index is 1.04 was improved by $311 \%$ when compared with that of a traditional SPR sensor. Furthermore; it was found that the decrease in the refractive index or the increase in the thickness of the low-refractive-index porous silica film can enlarge the FOM enhancement. It is believed that the proposed SPR sensor with a low-refractive-index porous silica film will be helpful for high-performance SPR sensors development.
\end{abstract}

Keywords: surface plasmon resonance sensor; figure of merit; porous silica; low-refractive-index

\section{Introduction}

The surface plasmon resonance (SPR) sensor, as an important optical sensor, has been used in chemical and biochemical sensing, gases sensing, medical diagnostics, and food safety detection for years [1-3]. The rapid development of SPR sensor technology is owed to its distinctive features, such as label-free quantification, real-time analysis, and high sensitivity [4-6]. Among the various types of SPR sensors, one of the widely used geometries is the Kretschmann configuration which is generally prepared by evaporating a thin metal film on top of a glass prism. In this configuration, p-polarized light illuminates on the metal surface from the prism side to excite the surface plasmon wave (SPW) [7]. When the incident angle of the light source fulfills the SPR requirements, the propagation constant of incident light along the interface will match that of the SPW [8], causing the collective oscillation of electrons on the surface of the metal $[9,10]$. In this case, the energy of incident light transfers onto the surface plasmons, which leads to a significant decrease in the reflectance, and forms a narrow dip in the reflectance spectrum [11]. Reflectance dip shifts, caused by the change of the analyte refractive index, can be used for sensing. For instance, in the angular interrogation mode, a change in the analyte refractive index causes a shift in the resonance angle (at which the minimum reflectance is realized) for a given wavelength [12].

The figure of merit (FOM), defined as the ratio between the sensitivity (S) and the full width at half maximum (FWHM) of the reflectance dip, is a comprehensive parameter to evaluate the performance 
of an SPR sensor [5]. According to the definition of FOM, improving the sensitivity is an immediate way to achieve FOM enhancement. In recent years, many investigations have been carried out for sensitivity improvement. For example, Lahav et al. [13] facilitated sensitivity enhancement by using a guided-wave SPR structure, which was prepared by evaporating a $10 \mathrm{~nm}$ Si layer on top of the metal. Shukla et al. [14] and Bao et al. [15] both demonstrated that the sensitivity of an SPR sensor could be increased by adding a $\mathrm{ZnO}$ thin film. Besides, Benkabou et al. [16] achieved sensitivity enhancement by employing the dielectric multilayer structure in the SPR sensor.

Although it has been demonstrated that the addition of a thin dielectric layer with a high-refractive-index on top of the metal layer can improve the sensitivity of an SPR sensor [11], the FOM of the SPR sensor cannot be enhanced in this way. The reason is as follows: this sensitivity improvement method induces a significant broadening of the reflectance dip, which causes the decreasing of the FWHM, consequently leading to no change, or even a decrease in FOM [17]. Compared with high-refractive-index dielectric thin films, the low-refractive-index dielectric thin films seem to be seldom used for the performance improvement of an SPR sensor. In this paper, we studied the effect of a low-refractive-index dielectric thin film on the performance of an SPR sensor, which has not been reported in literature yet.

As an example of a study, porous silica (a kind of low-refractive-index material) was considered because its refractive index can change from 1.05 to 1.46 by controlling its porosity [18]. Besides having a low-refractive-index, porous silica film has several other advantageous properties, such as low thermal conductivity, high mechanical strength, and excellent thermal stability [19]. These characteristics make it applicable to many optical aspects, such as the preparation of antireflection coatings [20]. Particularly, porous silica film has also been employed for performance improvement of an SPR sensor by reducing its FWHM of the reflectance dip [21].

Therefore, it will be of much interest in this paper to study in detail the effect of a porous silica film on the performance of an SPR sensor, and to explore the possibility of FOM enhancement by using porous silica film. To prevent the diffusion of analyte fluid into the porous silica film, which may affect its refractive index, a thin $\mathrm{SiO}_{2}$ film was used as a protective film at top of the SPR sensor (as shown in Figure 1). The obtained result indicated that by adding a $40 \mathrm{~nm}$ thick porous silica film with the porosity of $90 \%$ (corresponding to the refractive index of 1.04) on top of the metal film, the FOM can be enhanced by an increase factor of $311 \%$, compared with that of a traditional SPR sensor.

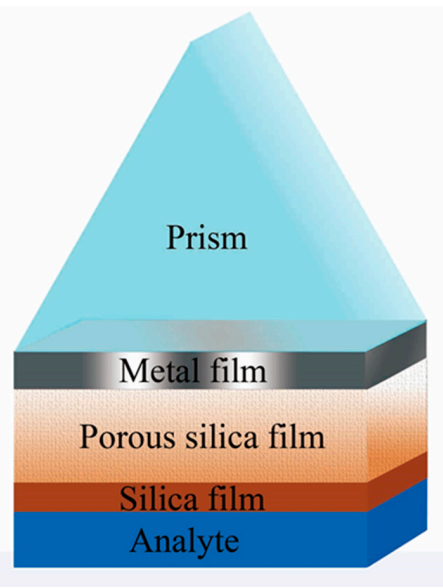

Figure 1. Schematic of the surface plasmon resonance (SPR) sensor with a porous silica film.

\section{Calculation Methods}

\subsection{Three-Layer Model}

To theoretically analyze the performance of an SPR sensor, we employed a typical thin-film theory [22], which has been widely validated with real SPR systems [23,24]. The SPR sensor with a 
porous silica film can be treated as a three-layer model (as shown in Figure 2), which contains a metal film, a porous silica film, and a silica film. The prism and analyte are considered as the incident and emergent media respectively.

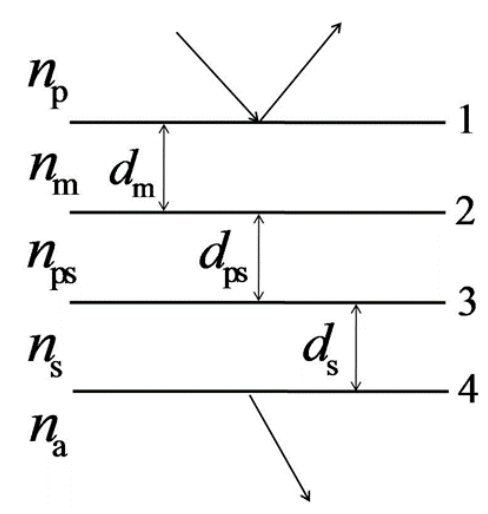

Figure 2. Three-layer model of the proposed SPR sensor.

\subsection{Reflectance Coefficient}

For this three-layer model, the tangential components of the electric and magnetic field amplitudes at interface $1\left(E_{1}\right.$ and $\left.H_{1}\right)$ are connected to those at interface $4\left(E_{4}\right.$ and $\left.H_{4}\right)$ by the characteristic matrix [22]. This is written as

$$
\left[\begin{array}{l}
E_{1} \\
H_{1}
\end{array}\right]=\left[\begin{array}{cc}
\cos \delta_{\mathrm{m}} & \frac{\mathrm{i}}{\eta_{\mathrm{m}}} \sin \delta_{\mathrm{m}} \\
\mathrm{i} \eta_{\mathrm{m}} \sin \delta_{\mathrm{m}} & \cos \delta_{\mathrm{m}}
\end{array}\right]\left[\begin{array}{cc}
\cos \delta_{\mathrm{ps}} & \frac{\mathrm{i}}{\eta_{\mathrm{ps}}} \sin \delta_{\mathrm{ps}} \\
\mathrm{i} \eta_{\mathrm{ps}} \sin \delta_{\mathrm{ps}} & \cos \delta_{\mathrm{ps}}
\end{array}\right]\left[\begin{array}{cc}
\cos \delta_{\mathrm{s}} & \frac{\mathrm{i}}{\eta_{\mathrm{s}}} \sin \delta_{\mathrm{s}} \\
\mathrm{i} \eta_{\mathrm{s}} \sin \delta_{\mathrm{s}} & \cos \delta_{\mathrm{s}}
\end{array}\right]\left[\begin{array}{c}
E_{4} \\
H_{4}
\end{array}\right],
$$

where $\delta_{\mathrm{i}}(\mathrm{i}=\mathrm{m}, \mathrm{ps}, \mathrm{s})$ and $\eta_{\mathrm{i}}(\mathrm{i}=\mathrm{m}, \mathrm{ps}, \mathrm{s})$ are the phase factor and the optical admittance of the metal $(\mathrm{m})$, porous silica (ps), or silica (s) film. $\delta_{\mathrm{i}}=2 \pi n_{\mathrm{i}} \mathrm{d}_{\mathrm{i}} \cos \theta_{\mathrm{i}} / \lambda$, in which $n_{\mathrm{i}}$ and $d_{\mathrm{i}}$ respectively represent the refractive index and thickness of each film. $\lambda$ is the wavelength of the incident light, and $\theta_{\mathrm{i}}$ represents the propagation angle in each medium. $\eta_{\mathrm{i}}=n_{\mathrm{i}} / \cos \theta_{\mathrm{i}}$ is satisfied for p-polarized light.

Because $H_{4} / E_{4}=\eta_{\mathrm{a}}$ (the optical admittance of the analyte) and $H_{1} / E_{1}=Y$ (the equivalent optical admittance of the assembly), Equation (1) can also be expressed as

$$
E_{1}\left[\begin{array}{l}
1 \\
Y
\end{array}\right]=\left[\begin{array}{cc}
\cos \delta_{\mathrm{m}} & \frac{\mathrm{i}}{\eta_{\mathrm{m}}} \sin \delta_{\mathrm{m}} \\
\mathrm{i} \eta_{\mathrm{m}} \sin \delta_{\mathrm{m}} & \cos \delta_{\mathrm{m}}
\end{array}\right]\left[\begin{array}{cc}
\cos \delta_{\mathrm{ps}} & \frac{\mathrm{i}}{\eta_{\mathrm{ps}}} \sin \delta_{\mathrm{ps}} \\
\mathrm{i} \eta_{\mathrm{ps}} \sin \delta_{\mathrm{ps}} & \cos \delta_{\mathrm{ps}}
\end{array}\right]\left[\begin{array}{cc}
\cos \delta_{\mathrm{s}} & \frac{\mathrm{i}}{\eta_{\mathrm{s}}} \sin \delta_{\mathrm{s}} \\
\mathrm{i} \eta_{\mathrm{s}} \sin \delta_{\mathrm{s}} & \cos \delta_{\mathrm{s}}
\end{array}\right]\left[\begin{array}{c}
1 \\
\eta_{\mathrm{a}}
\end{array}\right] E_{4} .
$$

So, the characteristic matrix of the assembly is

$$
\left[\begin{array}{l}
B \\
C
\end{array}\right]=\left[\begin{array}{cc}
\cos \delta_{\mathrm{m}} & \frac{\mathrm{i}}{\eta_{\mathrm{m}}} \sin \delta_{\mathrm{m}} \\
\mathrm{i} \eta_{\mathrm{m}} \sin \delta_{\mathrm{m}} & \cos \delta_{\mathrm{m}}
\end{array}\right]\left[\begin{array}{cc}
\cos \delta_{\mathrm{ps}} & \frac{\mathrm{i}}{\eta_{\mathrm{ps}}} \sin \delta_{\mathrm{ps}} \\
\mathrm{i} \eta_{\mathrm{ps}} \sin \delta_{\mathrm{ps}} & \cos \delta_{\mathrm{ps}}
\end{array}\right]\left[\begin{array}{cc}
\cos \delta_{\mathrm{s}} & \frac{\mathrm{i}}{\eta_{\mathrm{s}}} \sin \delta_{\mathrm{s}} \\
\mathrm{i} \eta_{\mathrm{s}} \sin \delta_{\mathrm{s}} & \cos \delta_{\mathrm{s}}
\end{array}\right]\left[\begin{array}{c}
1 \\
\eta_{\mathrm{a}}
\end{array}\right] .
$$

The equivalent admittance $Y$ can be calculated through $Y=C / B$, and the reflectance $R$ of the SPR sensor is

$$
R=\left|\frac{\eta_{\mathrm{p}}-Y}{\eta_{\mathrm{p}}+Y}\right|
$$

where $\eta_{p}$ is the optical admittance of the prism.

\subsection{Performance Parameters}

The performance of an SPR sensor can be described by several parameters, such as the resonance angle $\theta_{\text {res }}$, depth of $\operatorname{dip} R_{\text {res }}$ (the reflectance at the resonance angle), sensitivity, FWHM, and FOM. In the angular interrogation mode, the resonance angle $\theta_{\text {res }}$ changes with the refractive index of the analyte $n_{\mathrm{S}}$, so the sensitivity $S$ can be expressed as the ratio between the resonance angle variation $\Delta \theta_{\text {res, }}$ and the variation of refractive index of the analyte $\Delta n_{\mathrm{s}}$ as follows [5]:

$$
S=\frac{\Delta \theta_{\text {res }}}{\Delta n_{\mathrm{s}}}
$$


The FWHM can be determined by calculating the full width at half maximum of the reflectance $\operatorname{dip}\left(\Delta \theta_{0.5}\right)$, expressed as

$$
\mathrm{FWHM}=\Delta \theta_{0.5}
$$

Thus, the value of the FOM can be calculated by

$$
\mathrm{FOM}=\frac{S}{\mathrm{FWHM}} .
$$

\section{Results and Discussions}

The performance of a prism-based SPR sensor is generally determined by the wavelength and incident angle of the light source, the material and thickness of each film used in the SPR sensor, and the material of the prism and analyte [25]. In our simulations, a laser with $632.8 \mathrm{~nm}$ wavelength was taken as the incident light source. Silver (Ag) was applied as the metal material in the SPR sensor $\left(n_{\mathrm{m}}=0.13+3.99 \mathrm{i}\right)$, which can provide sharper reflectance dip than gold $(\mathrm{Au})[21,26]$. The thickness of the Ag film was assumed to be $47 \mathrm{~nm}$ to ensure an approximate-zero reflectance at the resonance angle. As mentioned above, a $10 \mathrm{~nm}$ thick $\mathrm{SiO}_{2}$ film was employed as the protective film $\left(n_{\mathrm{s}}=1.46\right)$. In addition, a 45-degree SF-11L glass was used as the prism $\left(n_{\mathrm{p}}=1.73205\right)$ in the SPR sensor [27], and water was considered as the analyte $\left(n_{\mathrm{a}}=1.33\right)$ in our simulations.

\subsection{The Refractive Index of Porous Silica}

To determine the effect of a porous silica film on the performance of an SPR sensor, the characteristic of the refractive index of the porous silica film needs to be studied in advance. The two-component Bruggeman approximation model [20] can be adopted to express the relationship between the refractive index and the porosity for porous silica film, which is written as

$$
P \frac{1-n^{2} \mathrm{ps}}{1+2 n^{2} \mathrm{ps}}+(1-P) \frac{n_{\mathrm{s}}^{2}-n^{2} \mathrm{ps}}{n^{2}{ }_{\mathrm{s}}+2 n^{2} \mathrm{ps}}=0,
$$

where $P$ is the porosity of the porous silica film, and $n_{\mathrm{s}}$ and $n_{\mathrm{ps}}$ are the refractive index of silica and porous silica, respectively. In this way, based on Equation (8), the relationship between the refractive index and the porosity can be determined, as shown in Figure 3.

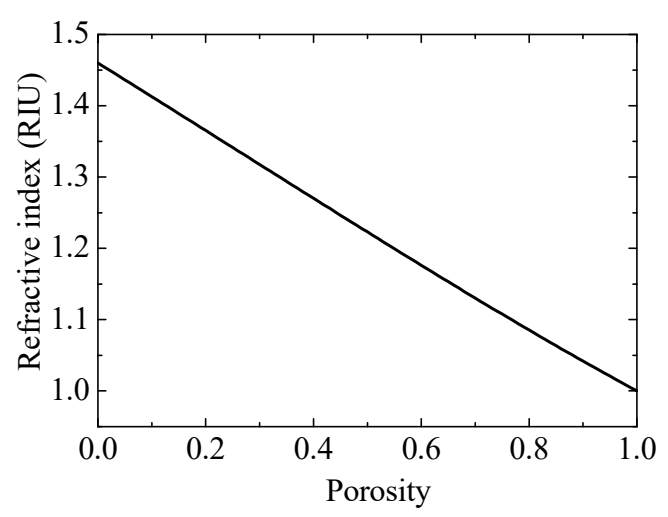

Figure 3. Refractive index as a function of the porosity of the porous silica film.

\subsection{The Effect of Porous Silica Film on the SPR Sensor}

In our study, the porous silica films with a refractive index of 1.365, 1.270, 1.176, and 1.086, corresponding to $20 \%, 40 \%, 60 \%$, and $80 \%$ porosity respectively, were chosen to explore the effect of a porous silica film on the performance of an SPR sensor. 


\subsubsection{Porous Silica with $20 \%$ Porosity $\left(n_{\mathrm{ps}}=1.365\right)$}

Firstly, we presented the effect of a porous silica film with $20 \%$ porosity $\left(n_{\mathrm{ps}}=1.365\right)$ on the performance of an SPR sensor. The angular spectra (reflectance versus incident angle) of the SPR sensors with 0 (traditional SPR sensor used for comparison), 20, and $40 \mathrm{~nm}$ thick $20 \%$ porosity porous silica film were plotted in Figure 4. The performance parameters for each sensor are listed in Table 1.

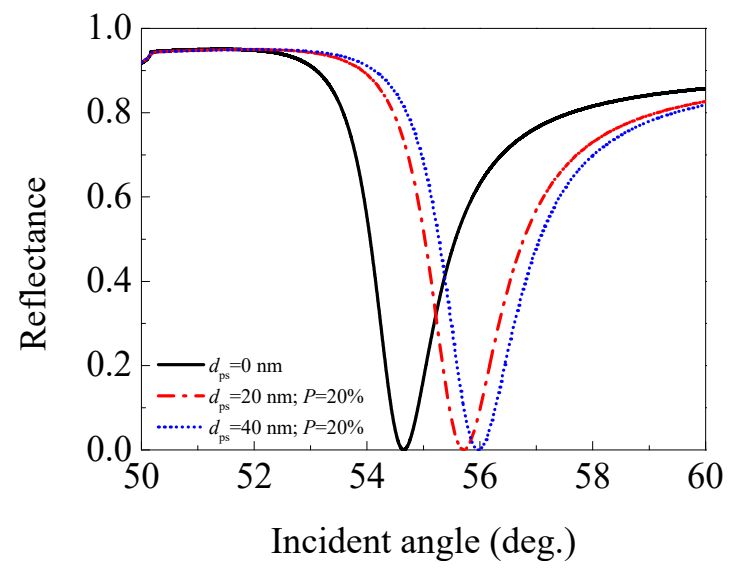

Figure 4. The angular spectra of the SPR sensors with 0 (traditional SPR sensor), 20, and $40 \mathrm{~nm}$ thick $20 \%$ porosity porous silica film $\left(n_{\mathrm{ps}}=1.365\right)$.

Table 1. The performance parameters of the SPR sensors with 0 (traditional SPR sensor), 20, and $40 \mathrm{~nm}$ thick $20 \%$ porosity porous silica film $\left(n_{\mathrm{ps}}=1.365\right)$.

\begin{tabular}{cccccc}
\hline $\begin{array}{c}\text { Thickness of Porous } \\
\text { Silica Film (nm) }\end{array}$ & $\begin{array}{c}\text { Resonance } \\
\text { Angle }\left(^{\circ}\right)\end{array}$ & Depth of Dip & Sensitivity $\left({ }^{\circ} / \mathbf{R I U}\right)$ & FWHM ( $\left.{ }^{\circ}\right)$ & FOM (RIU $^{-\mathbf{1}}$ ) \\
\hline 0 & 54.650 & $3.27 \times 10^{-4}$ & 67.9 & 1.513 & 44.888 \\
20 & 55.715 & $3.58 \times 10^{-4}$ & 53.7 & 1.751 & 30.654 \\
40 & 55.974 & $3.65 \times 10^{-4}$ & 43.8 & 1.784 & 24.550 \\
\hline
\end{tabular}

Compared with a traditional SPR sensor (without porous silica film, i.e., $d_{\mathrm{ps}}=0 \mathrm{~nm}$ ), the SPR sensor with a $20 \mathrm{~nm}$ ( or $40 \mathrm{~nm}$ ) thick $20 \%$ porosity porous silica film exhibits a slightly larger resonance angle and depth of dip (but $R_{\text {res }}<1 \times 10^{-3}$ ). In addition, the sensitivity decreases from $67.9^{\circ} /$ RIU for the traditional SPR sensor, to 53.7 (or 43.8) $/$ RIU for the SPR sensor with a $20 \mathrm{~nm}$ (or $40 \mathrm{~nm}$ ) porous silica film, but the FWHM increases from $1.513^{\circ}$ to $1.751^{\circ}$ (or $1.784^{\circ}$ ). Thus, the FOM decreases from $44.888 \mathrm{RIU}^{-1}$ to 30.654 (or 24.550) RIU ${ }^{-1}$. The results indicate that adding a $20 \mathrm{~nm}$ (or $40 \mathrm{~nm}$ ) porous silica film with $20 \%$ porosity $\left(n_{\mathrm{ps}}=1.365\right)$ in a traditional SPR sensor can decrease sensitivity and increase FWHM, which finally leads to the decreasing of the FOM.

\subsubsection{Porous Silica with $40 \%$ Porosity $\left(n_{\mathrm{ps}}=1.270\right)$}

Secondly, we showed the effect of a porous silica film with $40 \%$ porosity $\left(n_{\mathrm{ps}}=1.270\right)$ on the performance of an SPR sensor. Figure 5 plotted the angular spectra of the SPR sensors with 0, 20, and $40 \mathrm{~nm}$ thick $40 \%$ porosity porous silica film, and Table 2 lists the performance parameters for each sensor.

Unlike the former case of porous silica film with $20 \%$ porosity, the SPR sensor with a $20 \mathrm{~nm}$ (or $40 \mathrm{~nm}$ ) thick $40 \%$ porosity porous silica film exhibits a smaller resonance angle and depth of dip when compared with the traditional SPR sensor. Besides, the sensitivity decreases from $67.9^{\circ} /$ RIU for the traditional SPR sensor, to 50.7 (or 41.5) $/$ RIU for the SPR sensor with a $20 \mathrm{~nm}$ (or $40 \mathrm{~nm}$ ) porous silica film, with the FWHM also decreasing from $1.513^{\circ}$ to $1.467^{\circ}$ (or $1.320^{\circ}$ ). Consequently, the FOM decreases from $44.888 \mathrm{RIU}^{-1}$ to 34.565 (or 31.443) $\mathrm{RIU}^{-1}$. The decreasing of the FOM should be due to a larger rate of decrease in the sensitivity $(25.332 \%$ or $38.881 \%)$ than that of the FWHM $(3.040 \%$ 
or $12.756 \%$ ) when an additional $20 \mathrm{~nm}$ or $40 \mathrm{~nm}$ porous silica film with $40 \%$ porosity is employed. The results illustrate that adding a $20 \mathrm{~nm}$ (or $40 \mathrm{~nm}$ ) porous silica film, with $40 \%$ porosity $\left(n_{\mathrm{ps}}=1.270\right)$ in a traditional SPR sensor can cause the decrease in sensitivity, FWHM, and FOM.

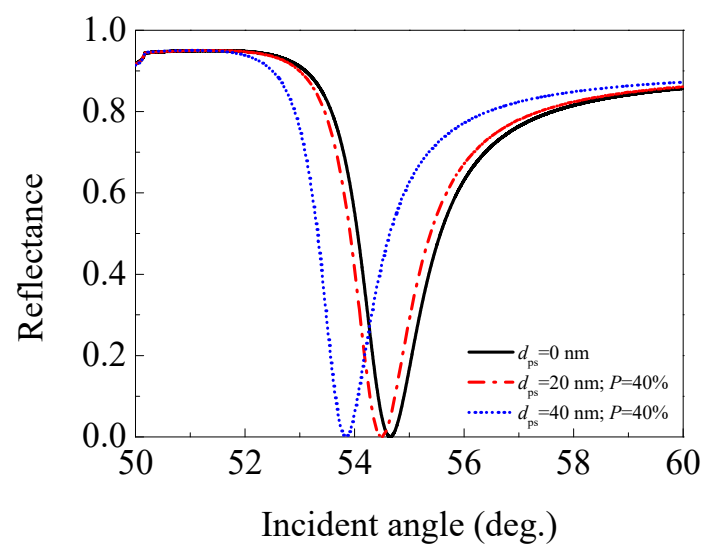

Figure 5. The angular spectra of the SPR sensors with 0 (traditional SPR sensor), 20, and $40 \mathrm{~nm}$ thick $40 \%$ porosity porous silica film $\left(n_{\mathrm{ps}}=1.270\right)$.

Table 2. The performance parameters of the SPR sensors with 0 (traditional SPR sensor), 20, and $40 \mathrm{~nm}$ thick $40 \%$ porosity porous silica film $\left(n_{\mathrm{ps}}=1.270\right)$.

\begin{tabular}{cccccc}
\hline $\begin{array}{c}\text { Thickness of Porous } \\
\text { Silica Film }(\mathbf{n m})\end{array}$ & $\begin{array}{c}\text { Resonance } \\
\text { Angle }\left(^{\circ}\right)\end{array}$ & Depth of dip & Sensitivity $\left({ }^{\circ} / \mathbf{R I U}\right)$ & FWHM $\left(^{\circ}\right)$ & ${\text { FOM }\left(\text { RIU }^{-1}\right)}^{-1}$ \\
\hline 0 & 54.650 & $3.27 \times 10^{-4}$ & 67.9 & 1.513 & 44.888 \\
20 & 54.493 & $3.22 \times 10^{-4}$ & 50.7 & 1.467 & 34.565 \\
40 & 53.837 & $3.00 \times 10^{-4}$ & 41.5 & 1.320 & 31.443 \\
\hline
\end{tabular}

\subsubsection{Porous Silica with $60 \%$ Porosity $\left(n_{\mathrm{ps}}=1.176\right)$}

Thirdly, the effect of a porous silica film with $60 \%$ porosity $\left(n_{\mathrm{ps}}=1.176\right)$ on the performance of an SPR sensor was presented. The angular spectra of the SPR sensors with 0 (traditional SPR sensor), 20, and $40 \mathrm{~nm}$ thick $60 \%$ porosity porous silica film were plotted in Figure 6, and the performance parameters for each sensor are listed in Table 3.

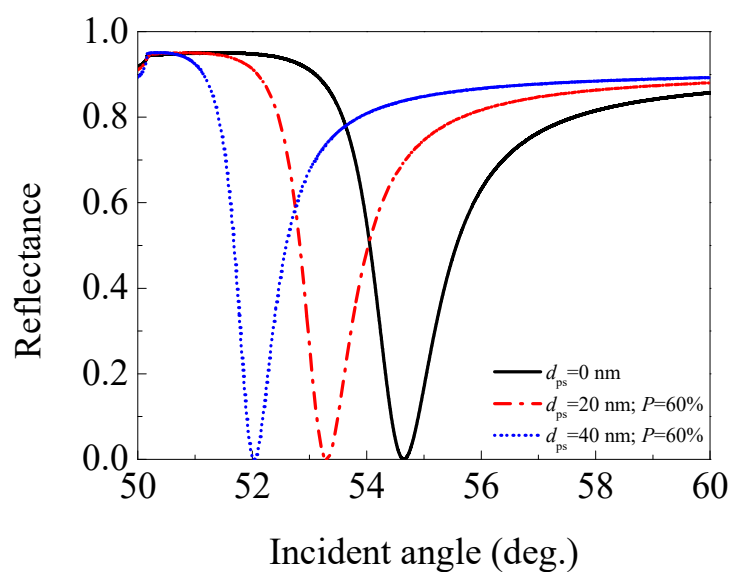

Figure 6. The angular spectra of the SPR sensors with 0 (traditional SPR sensor), 20, and $40 \mathrm{~nm}$ thick $60 \%$ porosity porous silica film $\left(n_{\mathrm{ps}}=1.176\right)$. 
Table 3. The performance parameters of the SPR sensors with 0 (traditional SPR sensor), 20, and $40 \mathrm{~nm}$ thick $60 \%$ porosity porous silica film $\left(n_{\mathrm{ps}}=1.176\right)$.

\begin{tabular}{cccccc}
\hline $\begin{array}{c}\text { Thickness of Porous } \\
\text { Silica Film (nm) }\end{array}$ & $\begin{array}{c}\text { Resonance } \\
\text { Angle }\left(^{\circ}\right)\end{array}$ & Depth of Dip & Sensitivity ( ${ }^{\circ} /$ RIU) & FWHM ( $\left.{ }^{\circ}\right)$ & FOM (RIU $^{-1}$ ) \\
\hline 0 & 54.650 & $3.27 \times 10^{-4}$ & 67.9 & 1.513 & 44.888 \\
20 & 53.299 & $2.82 \times 10^{-4}$ & 48.1 & 1.195 & 40.242 \\
40 & 52.034 & $2.39 \times 10^{-4}$ & 40.8 & 0.910 & 44.129 \\
\hline
\end{tabular}

The SPR sensor with a $20 \mathrm{~nm}$ (or $40 \mathrm{~nm}$ ) thick $60 \%$ porosity porous silica film still exhibits a smaller resonance angle and depth of dip than the traditional SPR sensor without porous silica film $\left(d_{\mathrm{ps}}=0 \mathrm{~nm}\right)$. The sensitivity decreases from $67.9^{\circ}$ / RIU for the traditional SPR sensor, to 48.1 (or 40.8$)^{\circ} / \mathrm{RIU}$ for the SPR sensor with a $20 \mathrm{~nm}$ (or $40 \mathrm{~nm}$ ) porous silica film, and the FWHM decreases from $1.513^{\circ}$ to $1.195^{\circ}$ (or $0.910^{\circ}$ ). Consequently, the FOM decreases from $44.888 \mathrm{RIU}^{-1}$ to 40.245 (or 44.129 ) RIU ${ }^{-1}$. The decreasing of the FOM still comes from the larger rate of decrease in the sensitivity $(29.161 \%$ or $39.912 \%)$ than that of the FWHM $(21.018 \%$ or $39.855 \%)$ when an additional $20 \mathrm{~nm}$ or $40 \mathrm{~nm}$ porous silica film with $60 \%$ porosity is used.

\subsubsection{Porous Silica with $80 \%$ Porosity $\left(n_{\mathrm{ps}}=1.086\right)$}

Finally, we presented the effect of a porous silica film with $80 \%$ porosity $\left(n_{\mathrm{ps}}=1.086\right)$ on the performance of an SPR sensor. The angular spectra of the SPR sensors with 0 (traditional SPR sensor used for comparison), 20, and $40 \mathrm{~nm}$ thick $80 \%$ porosity porous silica film were given in Figure 7, and the performance parameters for each sensor are listed in Table 4.

Similar to the case of $60 \%$ porosity porous silica film, the SPR sensor with a $20 \mathrm{~nm}$ (or $40 \mathrm{~nm}$ ) thick $80 \%$ porosity porous silica film also exhibits a smaller resonance angle and depth of dip than a traditional SPR sensor $\left(d_{\mathrm{ps}}=0 \mathrm{~nm}\right)$. The sensitivity decreases from $67.9^{\circ} / \mathrm{RIU}$ for the traditional SPR sensor, to 46.2 (or 42.9$)^{\circ} / \mathrm{RIU}$ for the SPR sensor with a $20 \mathrm{~nm}$ (or $40 \mathrm{~nm}$ ) thick $80 \%$ porosity porous silica film, while the FWHM decreases from $1.513^{\circ}$ to $0.934^{\circ}$ (or $0.505^{\circ}$ ). Surprisingly, the FOM does not decrease, but increases from $44.888 \mathrm{RIU}^{-1}$ to 49.646 (or 84.866) RIU ${ }^{-1}$. The reason for the increasing of the FOM should be attributed to the smaller rate of decrease in the sensitivity $(31.959 \%$ or $36.819 \%)$ than that of the FWHM (38.268\% or $66.623 \%)$ when an additional $20 \mathrm{~nm}$ or $40 \mathrm{~nm}$ porous silica film with $80 \%$ porosity is applied. This reflects the fact that adding a $20 \mathrm{~nm}$ (or $40 \mathrm{~nm}$ ) porous silica film with $80 \%$ porosity $\left(n_{\mathrm{ps}}=1.086\right)$ in a traditional SPR sensor can realize FOM enhancement.

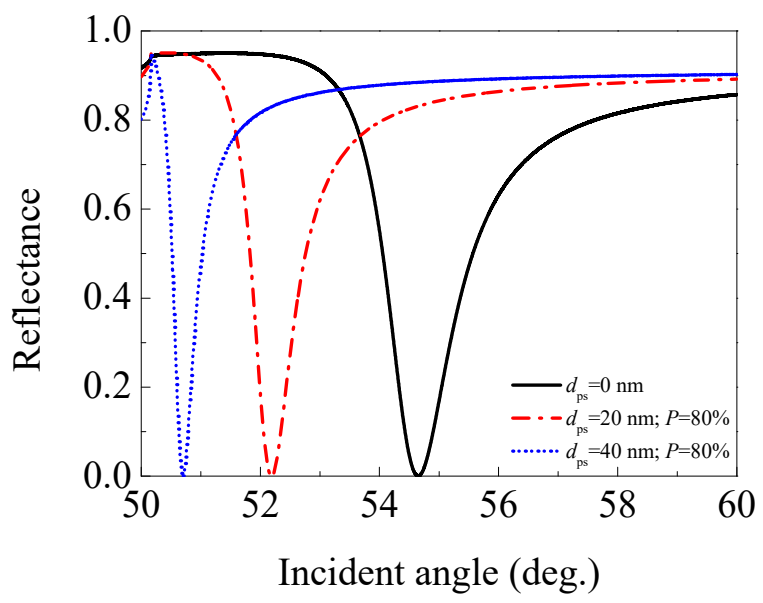

Figure 7. (Color online) The angular spectra of the SPR sensors with 0 (traditional SPR sensor), 20, and $40 \mathrm{~nm}$ thick $80 \%$ porosity porous silica film $\left(n_{\mathrm{ps}}=1.086\right)$. 
Table 4. The performance parameters of the SPR sensors with 0 (traditional SPR sensor), 20, and $40 \mathrm{~nm}$ thick $80 \%$ porosity porous silica film $\left(n_{\mathrm{ps}}=1.086\right)$.

\begin{tabular}{cccccc}
\hline $\begin{array}{c}\text { Thickness of Porous } \\
\text { Silica Film }(\mathbf{n m})\end{array}$ & $\begin{array}{c}\text { Resonance } \\
\text { Angle }\left(^{\circ}\right)\end{array}$ & Depth of Dip & Sensitivity $\left({ }^{\circ} / \mathbf{R I U}\right)$ & FWHM $\left(^{\circ}\right)$ & FOM (RIU $^{-1}$ ) \\
\hline 0 & 54.650 & $3.27 \times 10^{-4}$ & 67.9 & 1.513 & 44.888 \\
20 & 52.189 & $2.44 \times 10^{-4}$ & 46.2 & 0.934 & 49.464 \\
40 & 50.701 & $1.94 \times 10^{-4}$ & 42.9 & 0.505 & 84.966 \\
\hline
\end{tabular}

\subsubsection{Summary}

Based on the investigation results, we conclude that by adding a $20 \mathrm{~nm}$ or $40 \mathrm{~nm}$ porous silica film with $20 \%, 40 \%$, or $60 \%$ porosity in a traditional SPR sensor, the FOM of the sensor could not be enhanced. However, by adding a $20 \mathrm{~nm}$ or $40 \mathrm{~nm}$ porous silica film with $80 \%$ porosity, the FOM of the sensor can be significantly improved. The enhanced FOM can be as high as 1.89 times that of a traditional SPR FOM by using a $40 \mathrm{~nm}$ thick $80 \%$ porosity porous silica film. One can notice that whether the FOM may be enhanced or not depends on the porous silica film's porosity and thickness. It is worth exploring how the FOM varies with the refractive index (or porosity) and thickness of porous silica film.

\subsubsection{Origin of FOM Enhancement}

To further investigate the origin of FOM enhancement achieved by adding a $20 \mathrm{~nm}$ or $40 \mathrm{~nm}$ porous silica film with $80 \%$ porosity porous silica film in a traditional SPR sensor, we calculated the electric field intensity enhancement factor inside the SPR sensors as discussed in Figure 7. We utilized the method described by Shalabney and Abdulhalim [28], as shown in Figure 8. When adding a $20 \mathrm{~nm}$ (or $40 \mathrm{~nm}$ ) porous silica film with $80 \%$ porosity, the electric field intensity enhancement factor at the analyte interface inside the SPR sensor decreases from 7.20 to 2.92 (or 0.78), which is considered to be the reason for the decrease in sensitivity according to Reference [28]. Meanwhile, the maximum value of the electric field intensity enhancement factor increases from 7.20 to 7.60 (or 7.84), which is the origin of the decrease in FWHM as demonstrated by Chen et al. [29], and should be responsible for FOM enhancement.

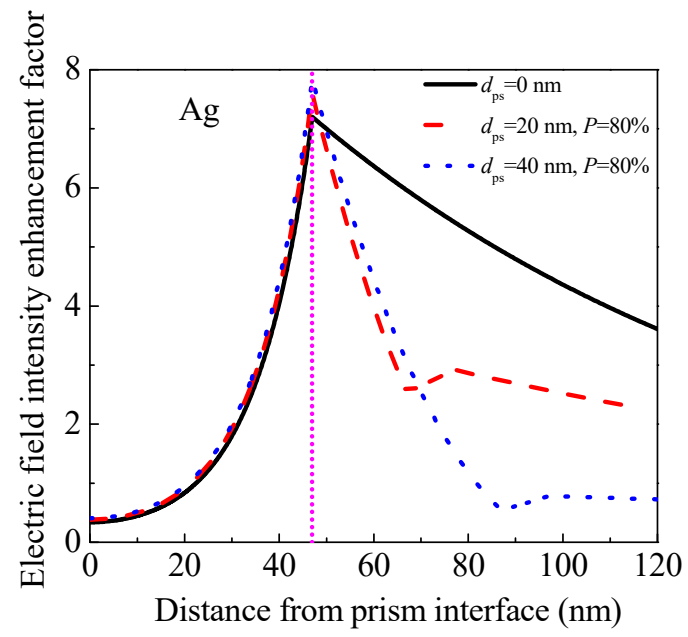

Figure 8. (Color online) Electric field intensity enhancement factor inside the SPR sensors in Figure 7.

\subsection{The Effect of a Porous Silica Film on an SPR Sensor}

We plotted the curves of the FOM versus the refractive index of the porous silica film with various thicknesses in Figure 9. Here, the porous silica films with 0 (traditional SPR sensor), 40, 80, and $120 \mathrm{~nm}$ 
thicknesses were considered. The results for only low depth of dip $\left(R_{\text {res }}<1 \times 10^{-2}\right)$ were shown in Figure 9.

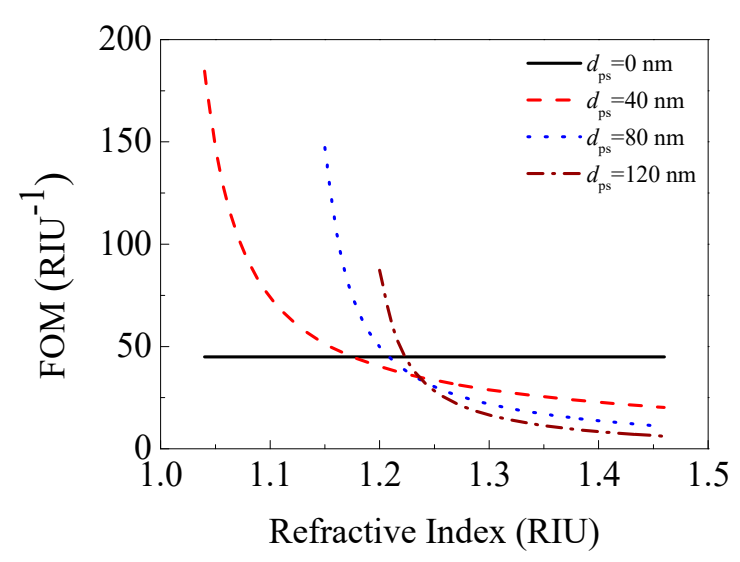

Figure 9. FOM versus the refractive index of porous silica film with various thicknesses.

In Figure 9, except for the FOM curve for $d_{\mathrm{ps}}=0 \mathrm{~nm}$ (traditional SPR sensor used for comparison), other FOM curves all go up with the decreasing of the refractive index of porous silica film. This indicates that the porous silica film with a lower refractive index (i.e., higher porosity) can realize a larger FOM. In addition, the FOM enhancement can be realized when the refractive index of the porous silica film is less than a critical value for a given film thickness. The critical refractive index is $1.162,1.202$, and 1.219 for 40, 80, and $120 \mathrm{~nm}$ thick porous silica film, respectively. Furthermore, the FOM enhancement increases with the thickness of the low-refractive-index porous silica film. However, with the increasing of the thickness, the depth of dip also rapidly increases, which degrades the signal-to-noise of the SPR sensor [11]. Under the condition of low depth of dip $\left(R_{\text {res }}<1 \times 10^{-2}\right)$, the largest FOM enhancement is achieved by adding a $40 \mathrm{~nm}$ thick porous silica film with $90 \%$ porosity $\left(n_{\mathrm{ps}}=1.04\right)$ in a traditional SPR sensor, which can enhance the FOM by an increase factor of $311 \%$.

\section{Conclusions}

The SPR sensor with a porous silica film has been theoretically investigated in this paper. Compared with a traditional SPR sensor, the SPR sensor with a porous silica film exhibited higher FOM when the refractive index of porous silica film is less than a critical value for a given film thickness. Particularly, the addition of a $40 \mathrm{~nm}$ porous silica film with $90 \%$ porosity $\left(n_{\mathrm{ps}}=1.04\right)$ in a traditional SPR sensor can improve the FOM by an increase factor of $311 \%$. The FOM enhancement is due to the smaller rate of decrease in the sensitivity than that of the FWHM when an additional low-refractive-index porous silica film is employed. In addition, the FOM enhancement becomes larger when the refractive index of a porous silica film becomes lower, or the thickness of the low-refractive-index porous silica film becomes larger. Although only porous silica film has been studied as an example in this paper, the principles and conclusions of FOM enhancement are also applicable to other low-refractive-index materials. This research provides a way for improving the FOM of a prism-based SPR sensor, and may be useful for high-performance SPR sensors development.

Acknowledgments: This work was supported by the National Key R\&D Program of China (No. 2016YFB0302000), the National Natural Science Foundation of China (Nos. 11547183 and 11547241), the Natural Science Foundation of Beijing (No. 2162033), and the Higher Education and High-quality and World-class Universities (No. PY201612).

Author Contributions: Qing-Qing Meng and Xin Zhao performed the simulations; Shu-Jing Chen analyzed the data; Ying-Chun Ding gave the suggestions; and, Cheng-You Lin and Zhao-Yang Chen wrote the paper.

Conflicts of Interest: The authors declare no conflict of interest. 


\section{References}

1. Nylander, C.; Liedberg, B.; Lind, T. Gas detection by means of surface plasmon resonance. Sens. Actuators 1982, 3, 79-88. [CrossRef]

2. Homola, J.; Yee, S.S.; Gauglitz, G. Surface plasmon resonance sensors: Review. Sens. Actuators B Chem. 1999, 54, 3-15. [CrossRef]

3. Tiwari, K.; Sharma, S.C.; Hozhabri, N. Hafnium dioxide as a dielectric for highly-sensitive waveguide-coupled surface plasmon resonance sensors. AIP Adv. 2016, 6, 045217. [CrossRef]

4. Pang, L.; Hwang, G.M.; Slutsky, B.; Fainman, Y. Spectral sensitivity of two-dimensional nanohole array surface plasmon polariton resonance sensor. Appl. Phys. Lett. 2007, 91, 123112. [CrossRef]

5. Maharana, P.K.; Jha, R.; Padhy, P. On the electric field enhancement and performance of SPR gas sensor based on graphene for visible and near infrared. Sens. Actuators B Chem. 2015, 207, 117-122. [CrossRef]

6. Zekriti, M.; Nesterenko, D.V.; Sekkat, Z. Long-range surface plasmons supported by a bilayer metallic structure for sensing applications. Appl. Opt. 2015, 54, 2151-2157. [CrossRef] [PubMed]

7. Roh, S.; Chung, T.; Lee, B. Overview of the characteristics of micro- and nano-structured surface plasmon resonance sensors. Sensors 2011, 11, 1565-1588. [CrossRef] [PubMed]

8. Matsubara, K.; Kawata, S.; Minami, S. Multilayer system for a high-precision surface plasmon resonance sensor. Opt. Lett. 1990, 15, 75-77. [CrossRef] [PubMed]

9. Verma, A.; Prakash, A.; Tripathi, R. Sensitivity enhancement of surface plasmon resonance biosensor using graphene and air gap. Opt. Commun. 2015, 357, 106-112. [CrossRef]

10. Sharma, N.K.; Yadav, S.; Sajal, V. Theoretical analysis of highly sensitive prism based surface plasmon resonance sensor with indium tin oxide. Opt. Commun. 2014, 318, 74-78. [CrossRef]

11. Shalabney, A.; Abdulhalim, I. Sensitivity-enhancement methods for surface plasmon sensors. Laser Photonics Rev. 2011, 5, 571-606. [CrossRef]

12. Yu, Z.; Fan, S. Extraordinarily high spectral sensitivity in refractive index sensors using multiple optical modes. Opt. Express 2011, 19, 10029-10040. [CrossRef] [PubMed]

13. Lahav, A.; Auslender, M.; Abdulhalim, I. Sensitivity enhancement of guided-wave surface-plasmon resonance sensors. Opt. Lett. 2008, 33, 2539-2541. [CrossRef] [PubMed]

14. Shukla, S.; Sharma, N.K.; Sajal, V. Sensitivity enhancement of a surface plasmon resonance based fiber optic sensor using ZnO thin film: A theoretical study. Sens. Actuators B Chem. 2015, 206, 463-470. [CrossRef]

15. Bao, M.; Li, G.; Jiang, D.M.; Chen, W.J.; Ma, X.M. Surface plasmon optical sensor with enhanced sensitivity using top $\mathrm{ZnO}$ thin film. Appl. Phys. A 2012, 107, 279-283. [CrossRef]

16. Benkabou, F.; Chikhi, M. Theoretical investigation of sensitivity enhancement in dielectric multilayer surface plasmon sensor. Phys. Status Solidi A 2014, 211, 700-704. [CrossRef]

17. Shalabney, A.; Abdulhalim, I. Figure-of-merit enhancement of surface plasmon resonance sensors in the spectral interrogation. Opt. Lett. 2012, 37, 1175-1177. [CrossRef] [PubMed]

18. Sobahan, K.; Park, Y.J.; Kim, J.J.; Hwangbo, C.K. Nanostructured porous $\mathrm{SiO}_{2}$ films for antireflection coatings. Opt. Commun. 2011, 284, 873-876. [CrossRef]

19. Yang, C.M.; Cho, A.T.; Pan, F.M.; Tsai, T.G.; Chao, K.J. Spin-on mesoporous silica films with ultralow dielectric constants, ordered pore structures, and hydrophobic surfaces. Adv. Mater. 2001, 13, 1099-1102. [CrossRef]

20. Astrova, E.V.; Tolmachev, V.A. Effective refractive index and composition of oxidized porous silicon films. Mat. Sci. Eng. B 2000, 69, 142-148. [CrossRef]

21. Yao, M.; Tan, O.K.; Tjin, S.C.; Wolfe, J.C. Effects of intermediate dielectric films on multilayer surface plasmon resonance behavior. Acta Biomater. 2008, 4, 2016-2027. [CrossRef] [PubMed]

22. Macleod, H.A. Thin-film optical filters, 4th ed.; CRC press: Boca Raton, FL, USA, 2010; pp. 21-61.

23. Lin, C.W.; Chen, K.P.; Hsiao, C.N.; Lin, S.M.; Lee, C.K. Design and fabrication of an alternating dielectric multi-layer device for surface plasmon resonance sensor. Sens. Actuators B Chem. 2006, 113, 169-176. [CrossRef]

24. Tiwari, K.; Shama, S.C.; Hozhabri, N. High performance surface plasmon sensors: Simulations and measurements. J. Appl. Phys. 2015, 118, 093105. [CrossRef]

25. Maharana, P.K.; Jha, R.; Palei, S. Sensitivity enhancement by air mediated graphene multilayer based surface plasmon resonance biosensor for near infrared. Sens. Actuators B Chem. 2014, 190, 494-501. [CrossRef] 
26. Jha, R.; Sharma, A.K. High-performance sensor based on surface plasmon resonance with chalcogenide prism and aluminum for detection in infrared. Opt. Lett. 2009, 34, 749-751. [CrossRef] [PubMed]

27. Lahav, A.; Shalabaney, A.; Abdulhalim, I. Surface plasmon sensor with enhanced sensitivity using top nano dielectric layer. J. Nanophotonics 2009, 3, 031501-031514. [CrossRef]

28. Shalabaney, A.; Abdulhalim, I. Electromagnetic fields distribution in multilayer thin film structures and theorigin of sensitivity enhancement in surface plasmon resonance sensors. Sens. Actuators A Phys. 2010, 159, 24-32. [CrossRef]

29. Chen, S.J.; Lin, C.Y. High-performance bimetallic film surface plasmon resonance sensor based on film thickness optimization. Optik 2016, 127, 7514-7519. [CrossRef]

2017 by the authors. Licensee MDPI, Basel, Switzerland. This article is an open access article distributed under the terms and conditions of the Creative Commons Attribution (CC BY) license (http://creativecommons.org/licenses/by/4.0/). 